such as the conservation of mass, energy and momentum, and I cannot see any way of positively ruling out a final product of the type suggested by Sir Oliver Lodge.

Nevertheless, the probabilities against the suggested occurrence would appear to be overwhelming. The "drawn-out jet" of which Sir Oliver Lodge speaks could be at best of meagre length. Sir George Darwin calculated the configurations at which stability could first be resumed and found that the length of gap available for the jet would be substantially less than the radius of the smaller star, at least so long as the mass-ratio lies within the limits observed in actual binary stars. (Diagrams are shown in Darwin's " Collected Works," iii. p. 508, or my "Problems of Cosmogony," p. 64.) In these calculations the stellar matter is assumed to be of uniform density; when allowance is made for the heterogeneity of actual matter, the length available for the jet is reduced almost, if not quite, to vanishing point. In confirmation of this, observation indicates very strongly that the two components of new-born binary stars are practically in contact. Thus I think Sir Oliver Lodge's process must probably be ruled out, not because it is dynamically impossible, but on the simpler grounds that there is no room for it to occur.

A further consideration seems to point forcibly in the same direction. Theory and observation agree in suggesting that fission into a double star cannot take place until the gas-laws are substantially departed from-i.e. somewhere about type B. But as the gas-laws are left behind, so also is the possibility of the formation by condensation of bodies with masses small in comparison with those of the bodies out of which they have come. If Sir Oliver Lodge's process could occur at all, it would not, I think, result in a " solar system," but in a multiple star in which all the constituents would be of comparable mass. The smaller masses ought at least to be susceptible to observation. But Russell has shown, quite convincingly, that known multiple systems satisfy the rather exacting criteria for systems which have been formed by successive fission, each fission forming only two bodies.

March 7 .

\section{Reminiscences of Prof. G. H. Quincke.}

THE obituary article on the late Prof. Quincke of Heidelberg in NATURE of February 23 gives an interesting review of the scientific activities of that very able experimenter. Readers of NATURE may be interested in a few personal reminiscences of a former student under Quincke.

The University of Heidelberg is housed in buildings in different parts of the town, the Physical Institute being situated on the High Street. There Quincke had not only his laboratory and lecture theatre, but also his private residence, to which he could retire at a step from the laboratory. The periods for practical work were from 9 A.M. to I P.M. and from 3 P.M. to 6 P.M. for those who took a full experimental course; the ordinary course was set forth in a list of more than $\mathbf{I} 20$ experiments, and before being allowed to proceed to research one had to do those experiments in the ordinary course which had not been done previously.

At that time (1894-95) Quincke had two assistants, whose emoluments were little better than those of Goldsmith's village preacher. The method of performing an experiment was described on an instruction sheet, a method not then in general use in our universities at home. It has been said that Quincke's apparatus consisted largely of "tin cans, glass tubes and sealing wax," but although much of the apparatus used by the student was of a simple character, there appeared to be no lack of good instruments when these were required. The wires necessary for electrical experiments had pins soldered on their ends which were stuck into cork mercury cups when in use ; after use, the wires were pinned up on a wall board. When taking observations requiring a steady eye, the observer was provided with a box seat, the dimensions of which offered three heights for the observer's head; the box could also be used on a table as a stand for apparatus.

Quincke had a laboratory mechanic called Pflug to whose expert assistance all were indebted; Pflug also acted as lecture assistant. The lectures on surface tension were, as might be expected, illustrated by many beautiful experiments, and continued for a whole week. While sitting in the darkened lecture theatre, and the blinds were about to be drawn up, it was somewhat disconcerting to the Englishspeaking student to hear the professorial order given : "Hell, Pflug, hell." On the occasion of the Geheimrath's birthday, we joined with the staff in offering our good wishes, and were taken upstairs forthwith to celebrate the event with a glass of wine. On two other occasions we were invited to partake of Quincke's hospitality, namely, at a grand ball in the Museum during the winter, and at a garden party in the summer.

One of Quincke's outstanding characteristics was his assiduity in experimenting. He recorded all his experimental results. In this connexion he once remarked that he had piles of note-books containing many unpublished results of his experiments. On one occasion the writer got into trouble for taking up a new part of the work before Quincke was satisfied that the previous part had been thoroughly explored.

Quincke followed out his principle "Immer arbeiten " to the ripe old age of eighty-nine. Peace to his ashes.

Natural Philosophy Institute,

The University, Glasgow, February 29.

The Twinkling of Distant Light-points.

Referring to Prof. Conrad's letter on "The Twinkling of the Stars," etc., published in NATURE of March 8, it may be of relevant interest to refer to the twinkling of the lights of coastal towns, as seen from a few miles at sea, on dark nights when the atmosphere is clear. Such pulsations are very conspicuous at times. I was under the impression that differences in the densities of air-layers produced the effect, but might not the wave-movements of the sea produce corresponding oscillations in the air above it, thus creating disturbances which would destroy optical continuity? Such twinkling of artificial lights at, practically, sea-level cannot be due to nitrogen-dust.

March 9. C. Carus-Wilson.

IN a letter in NATURE (Jan. 20, I92I; vol. I06, p. 66I) I took occasion to point out that the year of Ramanujan's birth was given in some notices as I 887 and in others as 1888 . I wrote at the time to Prof. Seshu Aiyar, of Madras, but my letter miscarried, and the question has only recently been put to him. He writes explicitly and emphatically, under date Feb. 20, I924: "The correct date of Ramanujan's birth as given in his horoscope preserved in his family is the 9th day of Margasirsha in the Samvat Sarvajit, answering to the English date of 22nd December, I887.'

University College, Reading,

E. H. Neville.

$$
\operatorname{March} 4 \text {. }
$$

NO. 2838 , voL. I I 3$]$$$
\text { March } 4 \text {. }
$$ 